Available online at https://jurnal.stmikroyal.ac.id/index.php/jurdima

\title{
PENERAPAN UU ITE DI INDONESIA SMA NEGERI 3 KISARAN
}

\author{
Ari Dermawan* ${ }^{1}$, Sumantri ${ }^{2}$, Sudarmin ${ }^{3}$ \\ ${ }^{1}$ Manaemen Informatika, STMIK Royal Kisaran \\ ${ }^{2,3}$ Sistem Informatika, STMIK Royal Kisaran \\ email: *aridermawan451@gmail.com
}

\begin{abstract}
The application of the ITE Law in Indonesia must be understood by all groups, not least for students of SMA Negeri 3 Kisaran. Providing information to all students regarding the application of Law No. 11/2008 on Information and Electronic Transactions (ITE) is a must to do, because now we see many school children vulnerable to violations of the ITE Law. The Information and Electronic Transaction Law (abbreviated as ITE Law) or Law number 11 of 2008 is the law that regulates information and electronic transactions, or information technology in general. This law has jurisdiction applicable to every person who commits legal acts as regulated in this Act, both within the territory of Indonesia and outside the jurisdiction of Indonesia, which has legal consequences in the jurisdiction of Indonesia and / or outside the jurisdiction of Indonesia and harm the interests of Indonesia. Many people want article 27 paragraph 3 in Law No. 11 of 2008 concerning Information and Electronic Transactions (ITE) for deletion. The reason is because article 27 paragraph 3 of the ITE Law which is commonly referred to as the rubber article is a dangerous law. Moreover, if applied by parties who do not understand about cyberspace.
\end{abstract}

Keywords: Application, Law

\begin{abstract}
Abstrak : Penerapan UU ITE di Indonesia harus benar-benar dipahami semua kalangan tidak terkecuali juga bagi siswa dan siswi SMA Negeri 3 Kisaran. Memberikan informasi kepada seluruh siswa-siswi berkaitan penerapan UU Nomor 11 Tahun 2008 tentang Informasi dan Transaksi Elektronik (ITE) merupakan hal yang harus dilaksanakan, sebab saat ini kita lihat banyak anak sekolah rentan terhadap pelanggaran UU ITE. Undang-undang Informasi dan Transaksi Elektronik (disingkat UU ITE) atau Undang-undang nomor 11 Tahun 2008 adalah UU yang mengatur tentang informasi serta transaksi elektronik, atau teknologi informasi secara umum. UU ini memiliki yurisdiksi yang berlaku untuk setiap orang yang melakukan perbuatan hukum sebagaimana diatur dalam Undang-Undang ini, baik yang berada di wilayah Indonesia maupun di luar wilayah hukum Indonesia, yang memiliki akibat hukum di wilayah hukum Indonesia dan/atau di luar wilayah hukum Indonesia dan merugikan kepentingan Indonesia. Banyak kalangan menginginkan pasal 27 ayat 3 di Undang-undang No. 11 tahun 2008 tentang Informasi dan Transaksi Elektronik (ITE) untuk dihapus. Alasannya, karena pasal 27 ayat 3 UU ITE yang biasa disebut dengan pasal karet sebagai undang-undang yang berbahaya. Terlebih lagi jika diterapkan oleh pihak-pihak yang tak paham soal dunia maya.
\end{abstract}

Kata kunci: Penerapan, Undang-Undang 
Available online at https://jurnal.stmikroyal.ac.id/index.php/jurdima

\section{PENDAHULUAN}

Penerapan UU ITE di Indonesia
harus benar-benar dipahami remua
kalangan tidak terkecuali juga bagi siswa
dan siswi SMA Negeri 3 Kisaran.
Memberikan informasi kepada reluruh
siswa-siswi berkaitan penerapan UU Nomor 11 Tahun 2008 tentang Informasi dan Transaksi Elektronik (ITE) merupakan hal yang harus dilaksanakan, sebab saat ini kita lihat banyak anak sekolah rentan terhadap pelanggaran UU ITE. Undangundang Informasi dan Transaksi Elektronik (disingkat UU ITE) atau Undang-undang nomor 11 Tahun 2008 adalah UU yang mengatur tentang informasi serta transaksi elektronik, atau teknologi informasi secara umum. UU ini memiliki yurisdiksi yang berlaku untuk setiap orang yang melakukan perbuatan hukum sebagaimana diatur dalam UndangUndang ini, baik yang berada di wilayah Indonesia maupun di luar wilayah hukum Indonesia, yang memiliki akibat hukum di wilayah hukum Indonesia dan/atau di luar wilayah hukum Indonesia dan merugikan kepentingan Indonesia.

Dengan adanya UU ITE ini, maka transaksi dan sistem elektronik beserta perangkat pendukungnya mendapat perlindungan hukum. Masyarakat harus memaksimalkan manfaat potensi ekonomi digital dan kesempatan untuk menjadi penyelenggara Sertifikasi Elektronik dan Lembaga Sertifikasi Keandalan. E-tourism mendapat perlindungan hukum. Masyarakat harus memaksimalkan potensi pariwisata indonesia dengan mempermudahlayanan menggunakan ICT.

Trafik internet Indonesia benar-benar dimanfaatkan untuk kemajuan bangsa. Masyarakat harus memaksimalkan potensi akses internet indonesia dengan konten sehat dan sesuai konteks budaya Indonesia. Produk ekspor indonesia dapat diterima tepat waktu sama dengan produk negara kompetitor. Masyarakat harus memaksimalkan manfaat potensi kreatif bangsa untuk bersaing dengan bangsa lain.
Berdasarkan permasalahan yang dijelaskan di atas, maka pengabdian masyarakat ini dilaksanakan untuk memahami kepada siswa dan siswi tentang penerapan UU ITE di Indonesia, serta bijak dalam memanfaatkan media sosial sebagai pemberi informasi kepada masyarakat, dan melindungi masyarakat pengguna jasa dengan memanfaatkan teknologi informasi.

UU ITE adalah bahwa pengaruh globalisasi dan perkembangan teknologi telekomunikasi yang sangat cepat telah mengakibatkan perubahan yang mendasar dalam penyelenggaraan dan cara pandang terhadap telekomunikasi. Kemunculan UU ITE membuat beberapa perubahan yang signifikan, khususnya dalam dunia telekomunikasi, seperti telekomunikasi merupakan salah satu infrastruktur penting dalam kehidupan berbangsa dan bernegara. Perkembangan teknologi yang sangat pesat tidak hanya terbatas pada lingkup telekomunikasi itu saja, melainkan sudah berkembang pada TI. Perkembangan teknologi telekomunikasi di tuntut untuk mengikuti norma dan kebijaksanaan yang ada di Indonesia.

UU ITE sudah cukup komprehensif dalam mengatur informasi elektronik dan transaksi elektronik. Hal ini dapat dilihat dari beberapa cakupan materi UU ITE yang merupakan terobosan baru yang sudah dijelaskan sebelumnya. Beberapa hal yang belum diatur secara spesifik diatur dalam UU ITE, akan diatur dalam Peraturan Pemeritanh dan peraturan perundangundangan lainnya.

Manfaat UU. No 11 Tahun 2008 tentang ITE, yaitu :

a) Menjamin kepastian hukum bagi masyarakat yang melakukan transaksi secara elektronik.

b) Mendorong pertumbuhan ekonomi Indonesia.

c) Sebagai salah satu upaya mencegah terjadinya kejahatan berbasis teknologi informasi.

d) Melindungi masyarakat pengguna jasa dengan memanfaatkan teknologi informasi. 
Available online at https://jurnal.stmikroyal.ac.id/index.php/jurdima

Dengan adanya UU ITE ini, maka transaksi dan sistem elektronik beserta perangkat pendukungnyamendapat perlindungan hukum. Masyarakat harus memaksimalkanmanfaat potensi ekonomi digital dan kesempatan untuk menjadipenyelenggara Sertifikasi Elektronik dan Lembaga Sertifikasi Keandalan. E-tourism mendapat perlindungan hukum. Masyarakat harusmemaksimalkan potensi pariwisata indonesia dengan mempermudahlayanan menggunakan ICT. Trafik internet Indonesia benar-benar dimanfaatkan untuk kemajuan bangsa. Masyarakat harus memaksimalkan potensi akses internet indonesia dengan konten sehat dan sesuai konteks budaya Indonesia. Produk ekspor indonesia dapat diterima tepat waktu sama dengan produk negara kompetitor. Masyarakat harus memaksimalkan manfaat potensikreatif bangsa untuk bersaing dengan bangsa lain.

Selain tujuan UU ITE kita juga harus memahami tujuan dari media sosial, agar kita dapat memahami tujuan sebenarnya dalam ber media sosial. Media sosial tentu memberikan dampak positif bagi para penggunanya yang benar-benar menggunakan media sosial tersebut sesuai dengan fungsi kehadirannya yaitu sebagai media untuk berkomunikasi, dan berbagi cerita. Karena sesungguhnya kehadiran teknologi adalah untuk membantu kehidupan menjadi yang lebih efisien, efektik serta lebih baik.

Berikut ini beberapa manfaat yang dirasakan dengan menggunakan media sosial dikutip dari laman trivia.id.

1. Mudah terinspirasi dan menjadi lebih kreatif, Media sosial memungkinkan kita mengekspresikan diri dengan berbagai bentuk media, mulai dari gambar, animasi, suara, hingga video! Mayoritas pengguna medsos pun memaksimalkan fitur-fitur yang ada dengan mengupload kreasi mereka dalam berbagai format. Latar belakang penggunanya pun sangat beragam, mulai dari seorang desainer, artist, fotografer, atau anak SMA sekali pun bisa menunjukan kreasinya. Maka, jika dulu kita perlu ke perpustakaan untuk mencari inspirasi, sekarang tinggal scrolling timeline, cari akun atau hashtagyang sesuai, maka semua ide terpapar di layar smartphonemu.

2. Kamu dapat berteman dan terhubung dengan siapa pun, Mendapatkan teman di media sosial, semudah tap jempol dua kali di postingan orang lain.

3. Jika beruntung, kamu juga bisa bertemu dengan jodohmu, Bethany Oslon dan Cory Staudacher saling mengenal melalui akun Instagram pada tahun 2011. Bethany tertarik saat melihat foto Cory yang diunggah oleh temannya. Dari Instagram, mereka pun berinteraksi melalui Facebook dan Twitter. Berbalas komentar, saling like foto masing-masing, hingga akhirnya bertemu di dunia nyata. Pasangan ini akhirnya berkencan dan menikah pada tahun 2014.

4. Tak ada lagi sekat dalam berkomunikasi, Sekitar tahun 2000-an, jika ingin berinteraksi dengan artis idola, kita bisa menelepon mereka, yang biasanya dijawab oleh mesin penjawab. Atau mengirimkan surat penggemar ke media cetak. Kini, menyapa idola bisa dilakukan dalam hitungan menit, bahkan detik. Tidak ada penghalang dalam komunikasi yang ingin kamu lakukan kepada siapa pun.

5. Beragam peluang bisnis bisa kamu temukan, Media sosial bukan hanya 'jalur' komunikasi dan media pengekspresian diri, lebih dari itu, terdapat banyak peluang bisnis melalui medsos. Sudah banyak kisah pengusaha muda yang sukses berkat berjualan di Instagram atau sukses menjadi selebgram.

6. Kamu semakin mudah mengetahui apa yang sedang terjadi di dunia, Jika dulu sumber informasi hanya dari buku, TV, radio atau koran, kini kamu tak perlu takut ketinggalan berita lagi. Cukup lihat apa yang trending di Twitter, atau 
Available online at https://jurnal.stmikroyal.ac.id/index.php/jurdima

pantau akun-akun medsos yang informatif, semua update yang terjadi bisa sampai kamu dapatkan dalam beberapa scrolling.

7. Menemukan orang-orang yang satu frekuensi denganmu, Media sosial memberikan banyak kemudahan dari berbagai aspek kehidupan. Beragam akun yang mewakili komunitas tertentu, memudahkan kamu tergabung dalam kelompok yang satu frekuensi denganmu, sekalipun berada di kota atau negara yang berbeda.

\section{METODE}

Kegiatan sosialisasi Penerapan UU ITE di Indonesia di SMA Negeri 3 Kisaran diselenggarakan dilakukan dalam tiga tahapan sebagai berikut:

\section{Tahap Persiapan}

Pada tahap ini dilakukan kegiatan pertemuan dengan pihak sekolah SMA Negeri 3 Kisaran dengan menjelaskan tentang adanya pemberian sosialisasi kepada siswa dan siswi SMA Negeri 3 Kisaran terkait dengan visi misi tim dalam pelaksanaan Tri Dharma Perguruan Tinggi, berkoordinasi dengan pihak sekolah mengenai sasaran peserta, syarat peserta, jumlah peserta, tempat Pembagian tugas kepada anggota tim, penyusunan materi dan persiapan pendukung lainnya.

\section{Tahap Pelaksanaan}

Pelaksanaan pelatihan ditujukan kepada 35 orang peserta yang memenuhi kriteria yaitu perwakilan setiap kelas yang ada di SMA Negeri 3 Kisaran. Kegiatan ini dilakukan dengan melakukan tatap muka interaktif dengan peserta, menggunakan media pembelajaran slide/power point untuk memudahkan para siswa dan siswi memahami materi sosialisasi.

\section{Tahap Evaluasi \\ Pada tahap evaluasi dilakukan penilaian keberhasilan peserta menangkap}

materi sosialisasi Penerapan UU ITE di Indonesia yang dilaksanakan di SMA Negeri 3 Kisaran. Para peserta diberikan kuesioner mengenai hal-hal berkaitan tentang UU ITE untuk melihat sejauh mana pemahaman Para peserta terhadap materi yang telah disampaikan. Kuesioner yang diberikan berisikan pertanyaan-pertanyaan tertutup.

\section{PEMBAHASAN}

Banyak kalangan menginginkan pasal 27 ayat 3 di Undang-undang No. 11 tahun 2008 tentang Informasi dan Transaksi Elektronik (ITE) untuk dihapus. Isi dari Pasal 27 ayat 3 UU ITE menyebutkan : melarang setiap orang dengan sengaja dan tanpa hak mendistribusikan dan/atau mentransmisikan dan/atau membuat dapat diaksesnya Informasi Elektronik dan/atau Dokumen Elektronik yang memiliki muatan penghinaan dan/atau pencemaran nama baik".

Alasannya, karena pasal 27 ayat 3 UU ITE yang biasa disebut dengan "pasal karet" sebagai undang-undang yang berbahaya. Terlebih lagi jika diterapkan oleh pihak-pihak yang tak paham soal dunia maya. Selain itu, pasal tersebut juga bisa digunakan dengan mudah untuk menjerat orang-orang demi membungkam kritik.

Adapun dampak jika pasal tersebut dihilangkan, efek jera terhadap para pelanggar hukum akan hilang. Dan ini juga bisa menambah permasalahan. Pasal tersebut sebenarnya memiliki peran besar dalam melindungi transaksi elektronik khususnya di dunia maya. Namun, hanya saja dalam penerapannya sering terjadi kesalahan. "Yang salah bukan pasal 27 ayat 3-nya, melainkan adalah penerapan dari pasal 27 ayat 3.

Akibat kesalahan penerapan tersebut, banyak telah menjadi "korban" dari UU ITE. Melihat UU ITE secara makro. Revisi adalah salah satu solusi agar tidak lagi ada korban akibat salah penerapan pasal. Solusi kedua adalah 


\section{Jurdimas (Jurnal Pengabdian Kepada Masyarakat) Royal}

Vol. 3 No. 1, Januari 2020, hlm. 59 - 64

DOI: https://doi.org/10.33330/jurdimas.v3i1.495

Available online at https://jurnal.stmikroyal.ac.id/index.php/jurdima

melakukan pembicaraan dengan aparat penegak hukum agar lebih hati-hati dalam menerapkan pasal ini di UU ITE.

Dari hasil sosialisasi penerapan UU ITE di Indonesia, kegiatan tersebut telah direalisasikan sesuai dengan rencana dan berjalan dengan lancar dan efektif.

Dari hasil pengolahan data kuesioner seluruh peserta memberikan respon yang positif (100\% menjawab ya untuk seluruh butir pertanyaan). Dari hasil ini maka diyakini peserta mendapatkan pengetahuan, pemahaman tentang apa itu UU ITE.

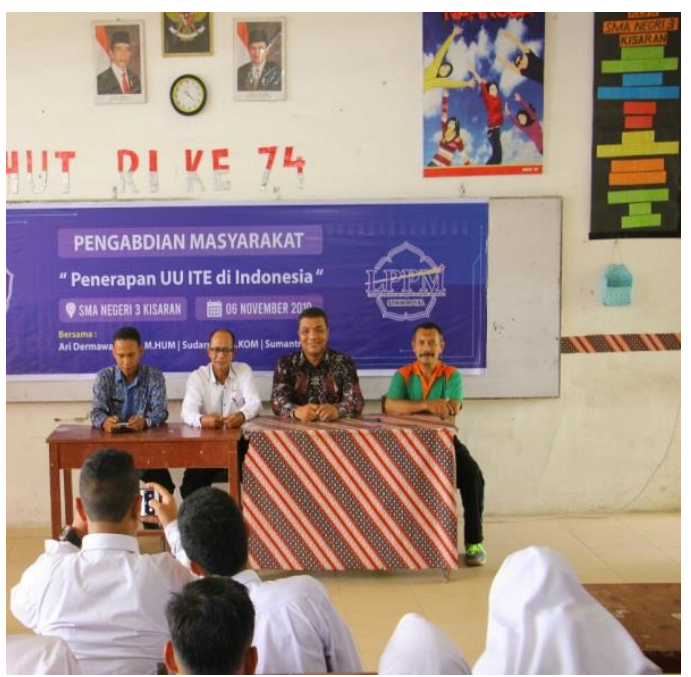

Gambar 1. Pembukaan Kegiatan

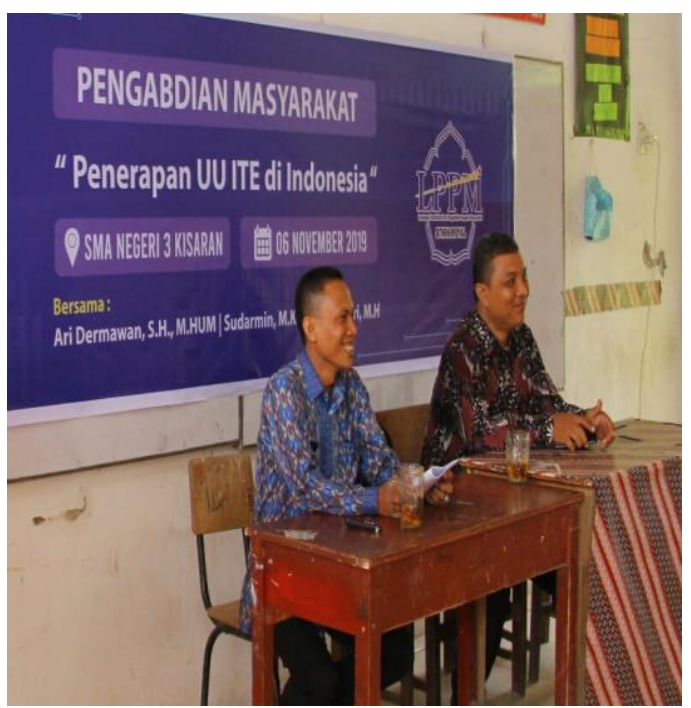

Gambar 2. Pengantar Penerapan UU ITE

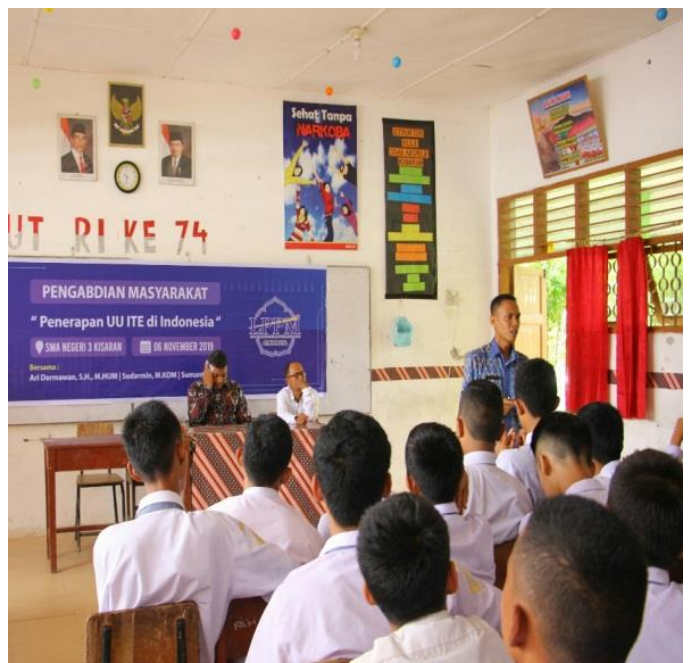

Gambar 3. Pemberian Materi UU ITE

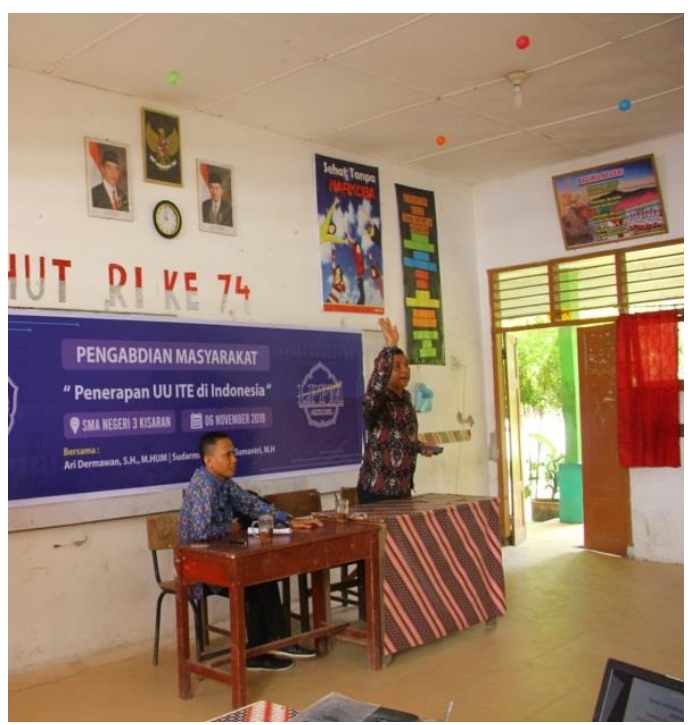

Gambar 4. Tanya Jawab Peserta

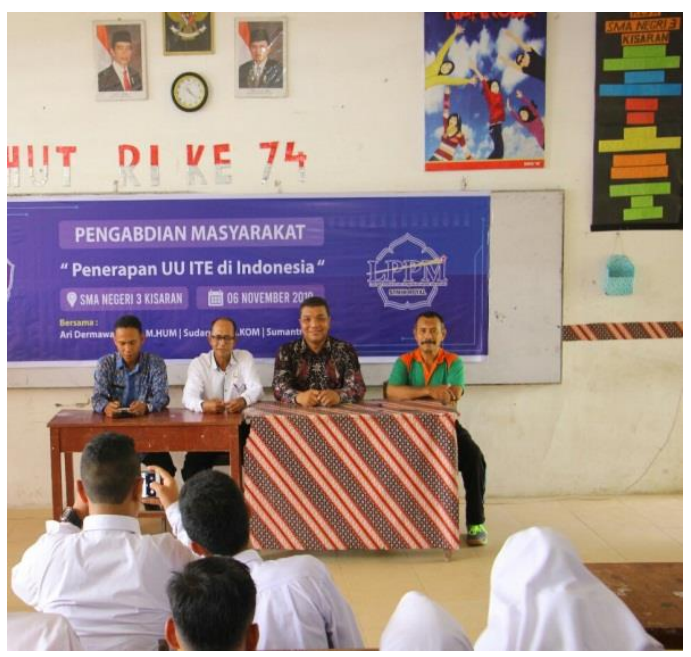

Gambar 4. Tanya Jawab Peserta 
Jurdimas (Jurnal Pengabdian Kepada Masyarakat) Royal

Vol. 3 No. 1, Januari 2020, hlm. 59 - 64

DOI: https://doi.org/10.33330/jurdimas.v3i1.495

ISSN 2622-3813 (Online)

Available online at https://jurnal.stmikroyal.ac.id/index.php/jurdima

\section{SIMPULAN}

Kesimpulan dari Kegiatan Pengabdian Masyarakat ini adalah : Dapat memberikan manfaat untuk Kepada siswa dan siswi SMA Negeri 3 Kisaran dalam hal penerapan UU ITE. Serta Para siswa dan siswi SMA Negeri 3 Kisaran dapat memahai hal-hal yang dilarang dalam media sosial.

\section{DAFTAR PUSTAKA}

Merry Magdalena dan maswigrantoro Roes Setiayadi, Cyberlaw, Tidak Perlu Takut, Andi, Yogyakarta, 2007.

Abdul Wahid dan Mohammad Labib, Kejahatan Mayantara (Cyber Crime), (Jakarta: PT. Refika Aditama, 2005.

Budi Suhariyanto, Tindak Pidana Teknologi Informasi (Cyber Crime) Urgensi Pengaturan dan Celah Hukumnya, Rajawali Pers, Jakarta, 2013. 